\title{
Identity Styles: Predictors of Reading and Writing Abilities
}

\author{
Zohre Mohamadi (Corresponding author) \\ English Teaching Department, Karaj Branch, Islamic Azad University, Karaj, Iran \\ E-mail: Zohre.mohamadi@kiau.ac.ir \\ Fariba Haji Mokhtari \\ English Teaching Department, Karaj Branch, Islamic Azad University, Karaj, Iran
}

Received: 15-04-2016

Published: 01-09-2016
Accepted: 18-06-2016

doi:10.7575/aiac.ijalel.v.5n.5p.102
Advance Access Published: July 2016

URL: http://dx.doi.org/10.7575/aiac.ijalel.v.5n.5p.102

\begin{abstract}
How the individual differences prime different learning process is well addressed in literature. But, what is missing from these analyses is how learners with different identity styles approach reading and writing skills and if different identity styles can predict differentiated language performance. The present study aims at investigating the relationship between identity styles, and reading/writing skills of Iranian intermediate female EFL learners. One the basis of the results of Nelson language proficiency test, 120 participants were selected to participate in this research. Participants' answers to Berzonsky's Identity Style Inventory (ISI3) and reading and writing parts of Preliminary English Test were analyzed. The results indicated that informational and normative identity styles were found to be positively correlated and diffuse-avoidant style was negatively correlated with reading and writing abilities whereas commitment identity didn't bear any significant relationships. The findings also indicated that informational style acted as the best predictor of these skills. Implications for language teachers are suggested.
\end{abstract}

Keywords: Reading and writing skills, Informational identity styles, normative identity styles, Diffuse avoidant style, Commitment style

\section{Introduction}

It is a long time that identity is a major construct in the social and behavioral science. Psychologists have conducted a large amount of research on the nature and development of identity and the relevant concepts such as self and selfidentity over many decades. What the word "Identity" basically describes is how a person answers the question "Who am I?" Sharma and Sharma (2010) said, "Identity is an umbrella term used throughout the social sciences to describe an individual's comprehension of himself or herself as a discrete, separate entity" (p. 119). Erikson (1968) believed that one of the most important developmental challenges that young adults and adolescents must successfully get over is the identity formation. When individuals face with a task related to the identity formation, they need to decide on very important issues in their lives like believing in a religion, adopting some political ideas or following a profession. In other words, in order to govern and regulate their lives effectively, individuals need to construct a balanced and meaningful identity structure, which enables them to preserve a sense of self-continuity across space and time and provides them with a particular set of beliefs and references that addresses interpreting experiences and self-relevant information, solving problems and making decisions (Vleioras \& Bosma, 2005).

In the case of language learning, the ways in which language learners perceive their relationship with the social world, how that relationship is developed over time and space, and how the learners become aware of opportunities for the future, are influenced by their identity.

Thus identity and language learning are closely related to each other. Furthermore, language learners' identity is suggested to be described as disposed to change, multiple and a site of struggle (Norton \& Toohey, 2001). According to Vleioras and Bosma (2005), particular features of the learners' personality and mind as well as the acquisition of a new set of lexical, grammatical and phonological rules are involved in L2 learning which may inhibit or support this process.

\section{Background and Purpose}

In order to understand the reasons of students' success and failure in English language learning, we need to examine the role of identity and self in this process. It is obvious that although researchers in other parts of the world have conducted a large number of studies on the second/foreign language learners' identity, the analysis of the relationship between EFL learning and learners' identity seems to be relatively disregarded in Iran. Thus there seems to be a clear need to enhance the knowledge of ELT research community of Iran in terms of the relationship between identity styles and language learning process, noting that this issue has largely gone unnoticed up to now.

Regarding this, the present study examined the performance of EFL learners in writing and reading based on Berzonsky's Identity Style Inventory scale. It is worth noting that Berzonsky (1988) presented a social-cognitive perspective and this perspective posit stylistic differences in how adolescents process and carry out tasks about information and issues which are related to identity. According to Berzonsky (1990), the interaction that people 
continually have with the social and physical world is what the identity develops in. It was believed that the occurrence of this developmental process is through cognitive constructions of individuals' sense of their identity (who people think they are) and their view toward the reality of life (Berzonsky, 1986, 1990, 2002). In this model, it is suggested that identity is a concept which is constructed by self, so the strategies that adolescents employ to form and sustain their identity should receive the main focus (Berzonsky, 2003).

Berzonsky's ISI scale seeks to classify how people respond to decisions. The scale sorts people according to whether they process through information-orientation, normative orientation, or diffuse-orientation. In most of the research done, Berzonsky uses these three dimensions. The third revision in 1992 is available for use and it adds commitment as a category (Berzonsky, 1993). This subscale was designed to assess strength of identity commitment, so it was referred to as the stability of decisions of personality (Berzonsky, 1992).

This model proposed that individuals with an informational identity style are self-reflective in relation to the issues which are relevant to identity and actively attempt to find process and evaluate information. An informational processing orientation is typical of adolescents who have doubts about self-construction and are interested in evaluating various dimensions of their identity (Berzonsky, 1990, 2004). Moreover, an informationally-oriented individual entails a willingness to investigate multiple solutions to a given problem and to explore several options before committing to any one (Berzonsky, 1993). These conscientious youth who employ openness to new experiences and enjoy their parents' support are associated with decisional planning, extroversion, cognitive complexity and psychological control (Berzonsky, 1990; Berzonsky \& Kuk, 2000, 2005; Berzonsky \& Neimeyer, 1994; Dollinger, 1995; Smits et al., 2008; Soenens, Duriez \& Goossens, 2005).

On the other hand, normative individuals try to conform to and rely on the expectations, prescriptions and values that the key figures in their lives (such as teachers, parents, authority figures) carry and consider them as appropriate. These individuals strictly accept their identity structure with no objection (Berzonsky, 2004). They rigidly hold organized commitments regarding their identity and attempt in a defensive way to save and maintain these commitments (Berzonsky, 1990). It was also reported that a normative style which employs inflexibility is regarded as highly committed. Moreover, a normative individual is associated with self-control and expects other people to favor blind submission (Duriez \& Soenens, 2006; Soenens et al., 2005). Additionally, according to Berzonsky (2004), the individuals with high normative scores display a low capacity to endure ambiguity and are highly closed regarding their cognition.

Berzonsky (1990) defined diffuse-avoidant individuals as those who defensively avoid and procrastinate the issue of decision making until a course of action is made necessary by situational demands. It is worth stating that these individuals try very hard to stay away from personal conflicts and the problems which are related to their identity. It was reported that the major characteristics of the adolescents with this type of identity style are dependence on maladaptive coping strategies (Berzonsky, 1992b; Soenens et al., 2005), behavioral disorders (Adams et al., 2001), tendency toward the feelings of shame (Lutwak, Ferrari \& Cheek, 1998) and pre-decisional fear (Berzonsky \& Ferrari, 1996). In addition, these individuals who are highly neurotic possess low level of conscientiousness and agreeableness (Dollinger, 1995; Duriez, Soenens \& Beyers, 2004). Although the adolescents with a diffuse-avoidant identity style have been found to score low on psychological control, cognitive persistence and awareness of their own personality, they score high on identity diffusion and cognitive strategies that do not function in a satisfactory way (Berzonsky \& Ferrari, 1996; Berzonsky \& Kuk, 2000, 2005; Dollinger, 1995; Smits et al., 2008).

In order to fulfill the objectives of the current study, the following research questions are proposed:

1. Does informational identity style have any relationship with reading comprehension and writing performance of Iranian intermediate EFL learners?

2. Does normative identity style have any relationship with reading comprehension and writing performance of Iranian intermediate EFL learners?

3. Does diffuse-avoidant identity style have any relationship with reading comprehension and writing performance of Iranian intermediate EFL learners?

4. Does commitment have any relationship with reading comprehension and writing performance of Iranian intermediate EFL learners?

5. To what extent do the identity styles predict reading comprehension and writing performance of Iranian intermediate EFL learners?

\section{Methodology}

Before conducing the first phase of the current study, the researchers obtained permission from the heads of Zabansara Foreign Language Institute for administration of the tests. The researchers also prepared a piece of paper for the participants explaining about the research and asked them about their consent to participate implying that there will be no extra credit as an advantage of participation but convincing them on the benefits of the findings of the study for foreign language learning.

The investigation in this research was completed in three main phases: First of all, the researcher gave the language proficiency test of Nelson $200 \mathrm{C}$ (as mentioned earlier) to 181 students in order to assess their level of proficiency. Then the researchers provided the subjects with some directions about the content of the test and the way they should answer the items. Following this, the participants answered the fifty-item Nelson test in 45 minutes. It is worth to say that after 
scoring the papers, approximately 60 students were excluded from the research because of their low score on this language proficiency test. Thus the Students whose scores were one standard deviation above and below the mean (Mean 18.64, SD 7.227) were estimated to be intermediate learners and selected as members of the sample.

In the second phase of investigation, the researchers administered the Iranian version of Berzonsky's Identity Style Inventory (ISI3) in order to specify the identity styles. Giving directions by the researcher about these 40 selfdescriptive statements and answering them by the students took approximately 25 minutes. For each individual, the number of items indicating each of his/her identity styles (as described in instrumentation) was computed and then the dominant identity style of that adolescent is determined.

In the third phase, the 120 homogeneous subjects were expected to complete the answer sheet of PET reading and writing in 90 minutes. In this stage, the participants were also provided with the directions, if needed. After scoring this standard test which included two raters for the writing part in order to get inter-rater reliability, suitable formulas of statistical package for social sciences (SPSS) that are illustrated in data analysis, were utilized for evaluating the relationships between the different identity styles of all the students with their reading comprehension and writing ability.

As mentioned in earlier, this study aimed at revealing the existence of the relationship between identity styles (based on Berzonsky's revised model), reading comprehension and writing ability of the Iranian Intermediate EFL learners. The related analysis and the results of the study are discussed as follow.

First, the findings of descriptive and inferential statistics of these two language skills along with the three identity styles (informational, normative and diffuse-avoidant) and the subscale of identity commitment are indicated with regards to each of the research questions. In the next phase, Correlations and regression indices are calculated in order to see the relationship between variables of the study.

\section{Data analysis}

\subsection{Descriptive Statistics}

The descriptive statistics of each of the scales included in the study are presented in Table 1 . These descriptive statistics represent mean, $\mathrm{SD}$, Cronbach's alpha and the number of participants.

Table 1. The Descriptive Statistics of the Study

\begin{tabular}{|c|c|c|c|c|c|}
\hline & $\begin{array}{l}\text { Cronbach's } \\
\text { alpha }\end{array}$ & Minimum & Maximum & Mean & Std. Deviation \\
\hline Writing & .81 & 4 & 20 & 15.89 & 3.748 \\
\hline reading & .76 & 18 & 35 & 27.50 & 4.928 \\
\hline Informational & .79 & 17.00 & 46.00 & 32.3193 & 5.04544 \\
\hline Normative & .80 & 16.00 & 44.00 & 27.1849 & 4.64861 \\
\hline Diffuse-avoidant & .83 & 15.00 & 38.00 & 28.6303 & 4.35280 \\
\hline Commitment & .76 & 19.00 & 40.00 & 28.8319 & 4.57391 \\
\hline
\end{tabular}

As shown in Table 1, the descriptive statistics show that all the scales have enjoyed an acceptable level of reliability. Moreover, the mean and SD of identity styles show that the level of students in normative and informational identity styles were approximately high based on Brezonskey (1990) and their diffuse/avoidance was average. Additionally, the learners' reading and writing scores were analyzed in terms of their level.

This should be noted that Cohen's Kappa for inter-rater reliability of writing scores was .82 which is strong. It is worth noting that the PET results reveal that the learners' L2 reading comprehension was more than average and their writing performance was high. 


\subsection{Correlation Analysis}

As mentioned above, the aim of the four research questions was investigating that whether there exists any relationship between the learners' identity styles and these two decoding and encoding language skills. In order to answer these questions, Pearson product moment correlations were calculated among the variables. Table 2 illustrates the related statistical calculations.

Table 2. The Correlations among Identity Styles, Reading, and Writing

\begin{tabular}{lcc}
\hline & \multicolumn{2}{c}{ Language skills } \\
\cline { 2 - 3 } & Reading & Writing \\
\hline Informational & $.559^{* *}$ & $.512 * *$ \\
Normative & $.338^{* *}$ & $.302 *$ \\
Diffuse-avoidant & $-.423^{* *}$ & $-.230 *$ \\
Commitment & .218 & .183 \\
\hline$p<.05$ & & \\
$* * p<.01$ & &
\end{tabular}

The findings indicated that the L2 learners' normative, informational, and diffuse identity styles were significantly related to their reading and writing ability. The results also showed that students' commitment did not significantly correlate with their reading $(r=.218)$ and writing ability $(r=.183)$. Whereas, informational identity style bore a significantly positive correlation with reading $(\mathrm{r}=.559, p<.01)$ and writing $(\mathrm{r}=.512, p<.01)$, and normative was also positively correlated with reading $(\mathrm{r}=.338, p<.01)$ and writing ability $(\mathrm{r}=.302, p<.05)$. On the other hand, diffuseavoidant identity style was negatively correlated with reading $(\mathrm{r}=-.423, p<.01)$, and writing $(\mathrm{r}=-.230, p<.05)$.

As it is indicated in table 2 , informational and normative identity styles are positively correlated and diffuse- avoidant identity styles are negatively correlated with reading and writing skills whereas the subscale of commitment has no significant relation with reading and writing performance of the EFL learners.

\subsection{Regression analysis}

The second round of analysis was to examine whether identity styles were able to predict L2 reading and writing. Therefore, the regression indices were calculated (noting that the regression assumptions including linearity, normality and homogeneity of variances were all calculated and the results revealed that there was no concern regarding their violation). The result of the regression analysis showed that the EFL learners' identity styles significantly predicted their reading and writing ability. First, the regression analysis was conducted for reading comprehension and identity styles.

Table 3. Betas, t level and Significance Level for the Multiple Linear Regression for Identity Styles and Reading

\begin{tabular}{|c|c|c|c|c|c|c|c|c|c|}
\hline \multirow[b]{2}{*}{$\begin{array}{l}\text { Language } \\
\text { skill }\end{array}$} & \multicolumn{3}{|c|}{ Informational } & \multicolumn{3}{|c|}{ Normative } & \multicolumn{3}{|c|}{ Diffuse-avoidant } \\
\hline & Beta & $\mathrm{t}$ & sig & Beta & $\mathrm{t}$ & sig & Beta & $\mathrm{t}$ & sig \\
\hline reading & 0.43 & 5.31 & 0.000 & 0.18 & 2.39 & 0.018 & .201 & 2.47 & 0.015 \\
\hline
\end{tabular}

As seen in the above table, informational identity style was the strongest predictor of Iranian EFL learners' performance in terms of reading comprehension $(t=5.31, p=.000)$. Moreover, the data analysis showed that normative identify style was the second best predictor of reading comprehension $(t=2.39, p=.018)$. The data analysis also showed that diffuseavoidant identity style negatively predicted reading comprehension of Iranian EFL learners $(t=-2.47, p=.015)$.

The next phase of the analysis included analyzing the regression indices for writing performance and identity styles of Iranian intermediate EFL learners. 


\begin{tabular}{|c|c|c|c|c|c|c|c|c|c|}
\hline \multirow{2}{*}{$\begin{array}{l}\begin{array}{l}\text { Identity } \\
\quad \text { styles }\end{array} \\
\text { Language } \\
\text { skill }\end{array}$} & \multicolumn{3}{|c|}{ Informational } & \multicolumn{3}{|c|}{ Normative } & \multicolumn{3}{|c|}{ Diffuse-avoidant } \\
\hline & Beta & $\mathrm{t}$ & sig & Beta & $\mathrm{t}$ & sig & Beta & $\mathrm{t}$ & sig \\
\hline Writing & 0.25 & 4.3 & 0.000 & 0.25 & 3.51 & 0.001 & 0.24 & 3.21 & 0.001 \\
\hline
\end{tabular}

As shown in table 4, informational identity style was again the strongest predictor of writing performance of Iranian EFL learners $(t=4.3, p=.000)$. Moreover, normative identify style also significantly predicted writing performance but in a weaker position comparing the informational style $(t=3.51, p=.001)$. The data analysis also indicated that diffuseavoidant identity style negatively predicted writing performance $(t=-3.21, p=.001)$ of Iranian EFL learners.

Based on the findings of the regression analysis (table 3 and 4), it was found that all identity styles were significant predictors of reading and writing in English. Getting back to the research questions of the study, it can be pointed that all identity styles were related to reading comprehension and writing performance but commitment as an indicator of identity strength had no relationship with the performance in these two skills.

\section{4 Results and Discussion}

The immediate objective of this study was to find out the existence of any relationship between informational identity processing orientation, reading comprehension and writing performance of the EFL learners in the context of Iran.

The results showed a positive correlation between informative individuals and their writing and reading ability. According to Kaplan and Flum (2010), the adolescents who are inclined toward the informational style are highly associated with proactive self-exploration. Furthermore, they are interested in gathering information, evaluating alternatives and making reasonable decisions.

Based on Berzonsky (1990) and Berzonsky and Kuk (2000), these individuals also process higher cognitive complexity, independence, problem-focused coping efforts, self-reflection, openness and motivation which all play crucial roles in second language acquisition.

The second objective was about the relationship between normative identity style, reading and writing ability of intermediate EFL learners. The distribution of scores in this study indicated that the normative-oriented individuals were also found to be positively correlated with reading comprehension and writing performance.

Since the research done in this field introduced the normative adolescents as possessing a well-defined sense of educational purpose (Berzonsky, 2003) and being extremely tied up in norms (Berzonsky, 1990), it can be inferred that these individuals are more likely to follow the standards and the rules they have previously learnt and use referent group's advices and suggestions in doing reading and writing tasks. According to Berzonsky and Kuk (2005), since the normative students have a high need for structure on how to do a task, they may function satisfactorily in wellstructured educational settings, so they obtain better scores comparing the diffuse-avoidant individuals. However, in more open-ended situations in which they have to engage in behavior monitoring and time managing, they may suffer from a disadvantage due to their lack of autonomy.

The third objective was to explore the connection between the diffuse-avoidant identity style and the two abovementioned language skills. Analyzing the data, the researchers came up with the result that this identity style failed to be positively correlated with each of these literacy components. This negative correlation is supported by the evidence that diffuse-avoidant adolescents are negatively correlated with cognitive persistence, self-reflection and conscientiousness (Berzonsky \& Ferrari, 1996).

It should also be mentioned that these adolescents extremely tend to delay decision making until a course of action is dictated by situational demands. Thus due to this avoidance which is the result of pre-decisional panic and also because of their dysfunctional cognitive strategies, these students perform poorly in reading comprehension and writing tasks. There are also a number of studies underlying that the diffuse-avoidant individuals are connected to the undesirable features that directly affect learning a new language. These characteristics include limited commitment, avoidant coping, self-handicapping, excuse making and efforts to rationalize negative performances (Berzonsky, 1990; Berzonsky \& Ferrari, 1996).

Investigation about the relation between commitment identity and reading and writing skills indicated existence of no relation.

As with last objective which seeks to find out the best predictor of reading and writing skills, the analysis recognized the informative adolescents as the best predictor of success and failure in both reading and writing skills which supported the findings of Berzonsky (2004) and Berzonsky and Kuk (2000, 2005). Concerning this, Kaplan and Flum (2010) also reported that the individuals using an informational style have an inclination to learn beyond the given tasks through seeking new information. In other words, these learners are more likely to engage in the activities which demand them to go beyond learning the presented materials. 
Regarding the strong association of these adolescents with autonomy, creativity and discovery in learning, it is also worth noting that their ability in making playful decisions can be considered as a decisive factor in planning, drafting and revising stages of writing and consequently developing a well-organized written task.

\section{Conclusion}

The overall results of the correlational analysis underlined that the individuals are inclined towards different identity styles and these identity styles are closely connected to linguistic performance of Iranian intermediate EFL learners, especially in terms of reading and writing skills.

Therefore, it can be concluded from the findings of the current study that the way the language learners tackle or approach new information or a subject area is an important issue in their reading comprehension and writing performance. Regarding this, while informationally-oriented individuals use their creativity, inferring ability and other mental resources to make sense of a reading text or to perform a writing task, normatively-oriented individuals use others' advices, suggestions and prescriptions to understand a reading text or to write in English. Moreover, diffuseavoidant adolescents try to avoid reading a passage or writing on given topics in English. The findings also indicated that the informational processing orientation is the best identity type that can act as the predictor of success or failure of the language learners in both reading and writing performance. Meanwhile, the normative identity style can also positively predict these language skills but in a weaker position in comparison with the informational style. Additionally, the statistical analysis displayed that diffuse -avoidant style negatively predicts reading and writing.

\section{References}

Berzonsky, M. D. (1986). Discovery versus constructivist interpretations of identity formation: Consideration of additional implications. Journal of Early Adolescence, 6, 111-117.

Berzonsky, M. D. (1988). Self-theorists, identity status, and social cognition. In D. K. Lapsley \& F. C. Power (Eds.), Self, ego, and identity: Integrative approaches (pp. 243- 262). New-York: Springer-Verlag.

Berzonsky, M. D. (1990). Self-construction over the life-span: A process perspective on identity formation. Advances in personal construct psychology, 1, 155-186.

Berzonsky, M.D. (1992). Identity style and coping strategies. Journal of Adolescent Research, 4, 771-786.

Berzonsky, M. D. (1992b). Identity style and coping strategies. Journal of Personality, 60, 771-788.

Berzonsky, M. D. (1993). A constructivist view of identity development: People as post- positivist self-theorists. In J. Kroger (Ed.), Discussions on ego identity (pp. 169- 183). Hillsdale, NJ: Erlbaum.

Berzonsky, M. D. (2002). Identity processing styles, self construction, and personal epistemic assumptions: A socialcognitive perspective. Paper presented at the workshop "Social Cognition in Adolescence: Its Developmental Significance', Groningen.

Berzonsky, M. D. (2003). Identity style and well-being: does commitment matter? Identity: An International Journal of Theory and Research, 3, 131-142.

Berzonsky, M.D. (2004). Identity processing style, self-construction, and personal epistemic assumptions: A socialcognitive perspective. European Journal of Developmental Psychology, 1, 303-315.

Berzonsky, M. D., \& Ferrari, J. R. (1996). Identity orientation and decisional strategies. Personality and Individual Differences, 20, $597-606$.

Berzonsky, M. D., \& Kuk, L. S. (2000). Identity status, identity processing style and the transition to university. Journal of Adolescent Research, 15, 81-98.

Berzonsky, M.D., \& Kuk, L. S. (2005). Identity Style, Psychosocial Maturity and academic performance. Personality and Individual Differences, 39, 235-247.

Berzonsky, M. D., \& Neimeyer, G. J. (1994). Ego identity status and identity processing orientation: The moderating role of commitment. Journal of Research in Personality, 28, 425-435.

Dollinger, S. M. (1995). Identity styles and the five-factor model of personality. Journal of Research in Personality, 29 , 475-479.

Duriez, B., \& Soenens, B. (2006). Personality, identity styles and authoritarianism. An integrative study among late adolescents. European Journal of Personality, 20, 397-417.

Duriez, B., Soenens, B., \& Beyers, W. (2004). Religiosity, personality, and identity styles: An integrative study among late adolescents in Flanders (Belgium). Journal of Personality, 72, 877-910.

Erikson, E. H. (1968). Identity: Youth and crisis. New York: Norton.

Kaplan, A., \& Flum, H. (2010). Achievement goal orientations and identity formation styles. Educational Research Review, 5, 50-67.

Lutwak, N., Ferrari, J. R., \& Cheek, J. M. (1998). Shame, guilt and identity in men and women:

The role of identity orientation and processing style in moral effects. Personality and Individual Differences, 25, 10271036. 
Norton, B., \& Toohey, K. (2001). Changing perspectives on good language learners. Quarterly, 35(2), $307-322$.

Sharma, S., \& Sharma, M. (2010). Self, social identity and psychological well-being. Psychological Studies, 55(2), 118-136.

Smits, I., Soenens, B., Luyckx, K., Duriez, B., Berzonsky, M., and Goossens, L. (2008). Perceived parenting dimensions and identity styles: Exploring the socialization of adolescents' processing of identity-relevant information. Journal of Adolescence, 31, 151-164.

Soenens, B., Duriez, B., \& Goossens, L. (2005). Social-psychological profiles of identitystyles: Attitudinal and socialcognitive correlates in late adolescence. Journal of Adolescence, 28, 107-125.

Vleioras, G., \& Bosma, H. A. (2005). Are identity styles important for psychological well-being? Journal of Adolescence, 28, 397-409. 